\title{
Adsorption and recovery of phosphate from aqueous solution by the construction and demolition wastes sludge and its potential use as phosphate-based fertiliser
}

\author{
Glaydson Simoes dos Reis ${ }^{\mathrm{a}, \mathrm{b}, \mathrm{c}, *}$, Bogdan Grigore Cazacliu ${ }^{\mathrm{b}}$, Catalina Rodriguez Correa ${ }^{\mathrm{d}}$, \\ Ekaterina Ovsyannikova $^{\mathrm{d}}$, Andrea Kruse ${ }^{\mathrm{d}}$, Carlos Hoffmann Sampaio ${ }^{\mathrm{a}, \mathrm{c}, \mathrm{e}}$, Eder Claudio Lima ${ }^{\mathrm{a}, \mathrm{f}}$, \\ Guillherme Luiz Dotto ${ }^{g}$ \\ ${ }^{a}$ Graduate Program in Metallurgical, Mine and Materials Engineering (PPGE3M), School of Engineering, Federal University of Rio Grande do Sul (UFRGS), Porto Alegre, \\ Brazil \\ ${ }^{\mathrm{b}}$ IFSTTAR, MAST, GPEM, F-44344, Bouguenais, France \\ ${ }^{\mathrm{c}}$ Department of Metallurgical Engineering, Federal University of Rio Grande do Sul (UFRGS), 9500 Bento Gonçalves Avenue, 91501-970, Porto Alegre, Brazil \\ ${ }^{\mathrm{d}}$ Department of Conversion Technologies of Biobased Resources, Institute of Agricultural Engineering, University of Hohenheim, Garbenstrasse 9, 70599, Stuttgart, \\ Germany \\ ${ }^{\mathrm{e}}$ Professor Serra Húnter Program, Department of Mine, Industrial and ICT Engineering, Polytechnical University of Catalonia, Barcelona, Spain \\ ${ }^{\mathrm{f}}$ Institute of Chemistry, Federal University of Rio Grande do Sul (UFRGS), Porto Alegre, RS, Brazil \\ ${ }^{g}$ Chemical Engineering Department, Federal University of Santa Maria, UFSM, Santa Maria, RS, Brazil
}

\section{A R T I C L E I N F O}

\section{Keywords:}

Recycling and valorisation

Construction and demolition waste sludge

Cheap and abundant adsorbent

Phosphorus adsorption

Potential fertiliser

\begin{abstract}
A B S T R A C T
This study aimed to investigate phosphate removal from aqueous effluents by an inorganic sludge from the inert part of construction and demolition wastes (CSW) as adsorbent. It is also discussed the application of the loaded $\mathrm{P}$ adsorbent as potential fertiliser. The CSW was also thermally treated at $800^{\circ} \mathrm{C}$ for $2 \mathrm{~h}(\mathrm{CSW}$-T), and its influence in the P removal was also investigated. The characterisation techniques highlighted low porosity on CSW and CSW-T adsorbents and that they are mainly formed by oxides which could enhance the $\mathrm{P}$ uptake and recovery. In $\mathrm{pH}$ experiments, $\mathrm{P}$ adsorption increased as initial $\mathrm{pH}$ increased, at $\mathrm{pH}$ higher than 7.8 the $\mathrm{P}$ removal sharply increased due to the formation of calcium phosphate precipitate. The mechanism of the $\mathrm{P}$ adsorption onto CSW indicated that the process was mainly controlled by chemical bonding or chemisorption. The results showed that CSW-T was more effective for P removal in comparison to CSW based on the Liu isotherm, the maximum sorption capacity attained was 24.04 (CSW) and $57.64 \mathrm{mg} \mathrm{g}^{-1}$ (CSW-T). Based on the Avrami's kinetic models, the time for attaining $95 \%$ of saturation was 212.6 (CSW), and $136.6 \mathrm{~min}$ (CSW-T). CSW and CSW-T showed the highest phosphate-removal performance among many adsorbents found in the literature; therefore, this kind of waste can be used widely as an inexpensive phosphate-recovery adsorbent. Besides, the P loaded adsorbents could be used as potential fertilisers which could be an interesting and efficient way of reuse for this waste.
\end{abstract}

\section{Introduction}

Nowadays, the rapid urbanisation, population growth and industrial development have to lead to severe environmental issues concerning wastes (e.g., solids and liquids) management in several countries [1]. One of the biggest challenges today is to promote the right management of a large number of solid wastes generated by human activities. Thus, new technologies need to be introduced to recycle and convert wastes into materials that can be reused or used as raw materials for new ecofriendly material fabrication [2,3]. This is an essential condition for environmental protection and sustainable development [1].

For instance, construction industry is a significant consumer of natural resources and the global aggregate production reaches to an enormous of 40 billion tons annually [1] and generates 2.65 billion tons of wastes [1]; therefore finding ways to reuse and recycle construction and demolition wastes is gaining importance due to legislation, it is

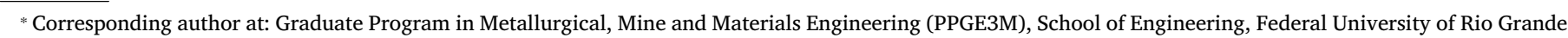
do Sul (UFRGS), Porto Alegre, Brazil.

E-mail address: glaydson.simoes@ufrgs.br (G.S. dos Reis). 


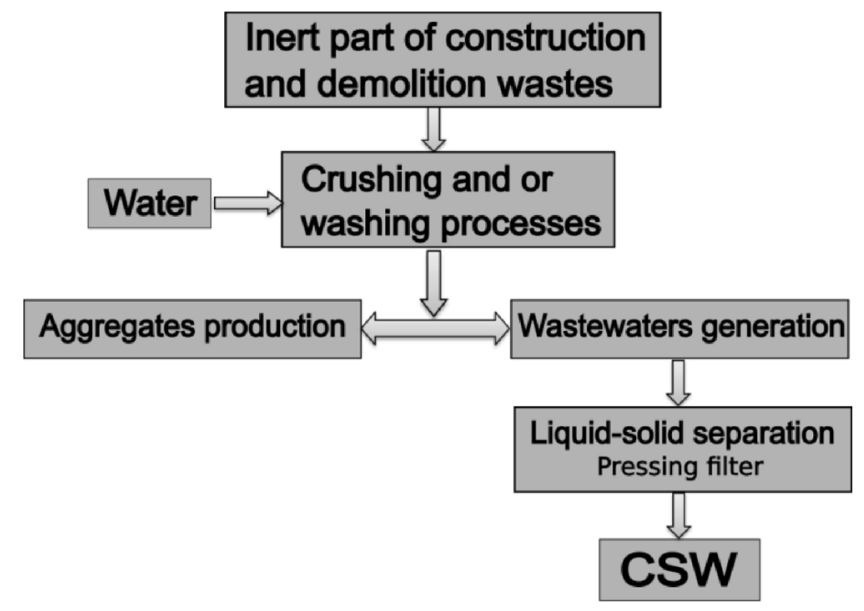

Fig. 1. Scheme for CSW generation at construction and demolition recycling wastes plant.

cheaper and available. Part of the solution for pollution problems associated with wastes generation can be solved by recycling them into the new materials for the desired application [2,3], such as adsorbents for removal of pollutants, or concentration of nutrients.

Inert part of the construction and demolition waste sludge (CSW) is a material which is neither chemically or biologically reactive and will not decompose. Examples of the main inert waste streams are concrete, bricks, masonry, tiles and ceramics, soil, debris. The use of CSW as a raw material for tackle water pollutants is a winning strategy to reach proper waste management and to reduce adverse environmental effects.

CSW has been primarily generated in many developed countries [4]. Its generation is due to either washing and/or crushing processes, in recycling plants, crushing and washing are essential to turn the inert part of construction and demolition wastes as recyclable aggregate materials (see Fig. 1 - scheme for CSW generation). The wet-based process is more commonly employed to remove impurities of the aggregates and reduce air pollution [4]. However, a significant amount of wastewater and, consequently, CSW are generated (see Fig. 1). This sludge contains very fine particles and high moisture content (nearly $93 \mathrm{wt} \%$ ) [4]. In order to optimise the solid/liquid separation, the sludge is flocculated, precipitated and dewatered in a press-filter. The water is recycled without any treatment, such as $\mathrm{pH}$ neutralisation [4]. Reuse of CSW as cheap adsorbent can be a successful strategy not only in terms of recycling but also by reducing costs with waste disposal and for diminishing the pollution problems associated to its land disposal $[1,4]$. Therefore it is imperative to explore the potential recycling of this type of waste, which can bring several benefits to its economic and environmental point of views [1,4]. Fewer type of solutions has been proposed for CSW reusing, being mostly of them into construction materials $[1,4]$. However, there is also a high potential of using CSW for eco-friendly environmental applications as an adsorbent for uptake pollutants in aqueous media [2,4]. There are few works reported in the literature that uses CSW as adsorbent [4-7].

The adsorption method is widespread and represents a cost-effective approach for solving many problems about the treatment of wastewaters [8-12]. An essential benefit of the adsorption process is because the used adsorbents can be regenerated and reutilised for many times, reducing the costs of the water treatment [8-12].

There are large numbers of efficient adsorbents existent in literature, and among them, activated carbons (ACs) are the most studied and employed, mainly due to their significant adsorptive characteristics $[13,14]$. Although activated carbon is an excellent adsorbent, new adsorbent materials need to be developed. CSW is a very cheap waste and can be used as a useful and efficient adsorbent [4-7].

Yoo et al., [4] studied the removal of three heavy metal salts (of $\mathrm{Cu}$, $\mathrm{Pb}$, and $\mathrm{Zn}$ ) in aqueous solutions by applying CSW and obtained outstanding efficiency removal. The formation of chemical bonds between the metal ions with carbonates released from calcite presented in CSW led to high removal efficiency. In addition to that, the metal ions might also be removed through the coprecipitation of metal hydroxides (M-OH) onto the surface of CSW under high $\mathrm{pH}$ conditions.

Jelić et al., 2018 [5], used samples of waste concrete, and façade for the adsorption of $\mathrm{Co}^{2+}, \mathrm{Ni}^{2+}$, and $\mathrm{Sr}^{2+}$, however the values of sorption capacity obtained for all these 3 elements were very low as $5-102 \mu \mathrm{g}$ $\mathrm{g}^{-1} \mathrm{Sr}^{2+}, 6.6-26.2 \mu \mathrm{g} \mathrm{g}^{-1} \mathrm{Co}^{2+}$, and $21-30 \mu \mathrm{g} \mathrm{g}^{-1} \mathrm{Ni}^{2+}$. These values of sorption capacity are minimal for being used in a real application.

Coleman et al., 2005 [6], observed that using batch-contact adsorption study confirmed that crushed concrete, in the particle size range $1-2 \mathrm{~mm}$, adsorbed $\mathrm{Cu}^{2+}\left(35 \mathrm{mg} \mathrm{g}^{-1}\right), \mathrm{Zn}^{2+}\left(33 \mathrm{mg} \mathrm{g}^{-1}\right)$, and $\mathrm{Pb}^{2+}\left(37 \mathrm{mg} \mathrm{g}^{-1}\right)$ successfully from aqueous solutions.

Egemose et al. 2012 [7], used crushed concrete material for adsorption of $\mathrm{P}$. The removal of $\mathrm{P}$ was favoured at basic solutions ( $\mathrm{pH} 12)$. The sorption capacity obtained ranged from $5.1-19.6 \mathrm{mg} \mathrm{g}^{-1}$.

In this work, for the first time, CSW is employed in phosphate removal aiming agricultural uses. Phosphate is a vital nutrient that is essential for life. It is a crucial component added in fertilisers for food production and has no substitute; therefore, recovering phosphate from wastewaters is imperative [15-17]. Concentrations of phosphate in surface waters even in the tiny range of 0.01 to $0.1 \mathrm{mg} \mathrm{L}^{-1} \mathrm{P}$ can lead to its eutrophication, which poses a substantial risk to the ecosystem resulting in environmental as well economic damage $[15,17]$. The presence of phosphate in natural waters comes from diffuse sources such as agricultural run-offs and municipal wastewater treatment plants $[15,16]$. Hence there is a need for technology that can effectively reduce the phosphorus to concentrations in the sub microgram levels.

Therefore, the overarching purpose of this study is to investigate the use of the inert part of the construction and demolition wastes sludge from a recycling plant for removal/recovery phosphate from aqueous solutions and discuss its potential use as fertiliser.

\section{Materials and methods}

\subsection{Materials}

All the reagents were analytical grade and used as received without any further purification. Potassium phosphate dibasic $\left(\mathrm{K}_{2} \mathrm{HPO}_{4}\right)$ was purchased from Sigma-Aldrich (DE). Deionised water and ethanol were procured from Beijing Chemical Reagents Company (China).

\subsection{CSW adsorbents}

The CSW sample used in this study was collected from a recycling demolition and construction waste plant in Frejus, south of France. The samples were collected just after the press filter with a moisture content of $32 \mathrm{wt} . \%$. The moisture level in the CSW was determined by ovendrying the sample at $105^{\circ} \mathrm{C}$ until constant weight. The sample was milled and sealed to avoid the decline of both $\mathrm{Ca}^{2+}$ concentration and $\mathrm{pH}$ that happens via natural carbonation (reaction between $\mathrm{Ca}^{2+}$ and atmospheric $\mathrm{CO}_{2}$ ).

Two CSW samples were evaluated as adsorbents: one is named as CSW (unmodified) and the second one as CSW-T (thermally treated CSW). The heating process took place in a laboratory electric furnace with a heating rate of $6 \mathrm{~K} \mathrm{~min}^{-1}$, and dwelled for $2 \mathrm{~h}$ at the maximum temperatures at $800^{\circ} \mathrm{C}$; afterwards, the furnace was shut down, and the sample was cooled down for $4 \mathrm{~h}$ inside the furnace until room temperature.

\subsection{Microstructure and chemical characteristics of the adsorbents}

The textural characterisation was carried out using $\mathrm{N}_{2}$ adsorptiondesorption isotherms at liquid $\mathrm{N}_{2}$, using a Tristar II $\mathrm{Kr} 3020$ 
Micromeritics equipment. Prior analyses, the samples were degassed at $120^{\circ} \mathrm{C}$ under vacuum. The specific surface area was determined by BET (Brunauer, Emmett and Teller) method.

The chemical composition of the CSW and CSW-T was analysed by $\mathrm{X}$-ray fluorescence (XRF) and wavelength Dispersive (WD-XRF) by using an S2 PICOFOX TXRF (Bruker AXS Microanalysis). Before analysis, around $10 \mathrm{~g}$ of each one of the adsorbents were grounded at particle size below 80 microns to perform the XRF analysis.

The mineralogical composition of the adsorbents was analysed using powder X-ray diffraction instrument (Siemens). The adsorbents were grounded at particle size below 80 microns to perform the XRF analysis. XRD patterns were obtained with a Diffrac 5000 BRUKER diffractometer (USA) operating at $45 \mathrm{kV}$ and $40 \mathrm{~mA}$ using $\mathrm{Cu}-\mathrm{K} \alpha$ monochromatic radiation $\left(\lambda=1.54 \AA\right.$ ), $2 \theta$ angle interval of $2-72^{\circ}$ with a counting time of $5 \mathrm{~s} /$ pass.

Scanning Electron Microscopy (SEM) was used to observe microstructures of both CSW and CSW-T by using an electron microscope JEOL (model SM 840). The samples were metalised with gold by using an ion sputtering device JEOL (model JFC 1100) to obtain the SEM images.

\subsection{Adsorption studies}

Amounts of $20.00 \mathrm{~mL}$ of $20.00-950.0 \mathrm{mg} \mathrm{L}^{-1}$ (at different initial pHs, from 2.0 to 11.0 ) of $\mathrm{P}$ (as $\mathrm{K}_{2} \mathrm{HPO}_{4}$ ) were placed into $50.0 \mathrm{~mL}$ Falcon flat tubes with several amounts $(0.03-0.5 \mathrm{~g})$ of CSW adsorbents. The flasks were capped and placed horizontally in a shaker, and the system was agitated between $5 \mathrm{~min}$ to $8 \mathrm{~h}$ [8-10]. Afterwards, to separate the solid and liquid phases, the tubes were centrifuged, and aliquots of $1-5 \mathrm{ml}$ were collected and diluted adequately in $10.0 \mathrm{ml}$ gauged flasks with proper blank solution [8-10].

The residual $\mathrm{P}$ (phosphate) concentrations before and after adsorption tests were quantified by using ICP-OES technique with equipment Agilent 715. The amount of $\mathrm{P}$ adsorbed by the adsorbents and the percentage of removal were calculated using Eqs. (1) and, (2), respectively [8-10]:

$q=\frac{(\mathrm{Co}-\mathrm{Cf})}{\mathrm{m}} \cdot \mathrm{V}$

$\%$ Removal $=100 \cdot \frac{(\mathrm{Co}-\mathrm{Cf})}{\mathrm{Co}}$

$\mathrm{q}$ is the quantity of $\mathrm{P}$ ions removed by the CSW absorbents in $\mathrm{mg} \mathrm{g}^{-1}$, $\mathrm{C}_{\mathrm{o}}$ is the initial $\mathrm{P}$ concentration in the solution in $\mathrm{mg} \mathrm{L}^{-1}, \mathrm{C}_{\mathrm{f}}$ is the $\mathrm{P}$ concentration after the batch adsorption experiment in $\mathrm{mg} \mathrm{L}^{-1}, \mathrm{~m}$ is the mass of CSW adsorbents in $\mathrm{g}$ and $\mathrm{V}$ is the volume of $\mathrm{P}$ solutions in contact with the CSW adsorbents in L [8-10].

\subsubsection{Analytical control of the measurements}

See Supplementary Material and references [18-22].

\subsubsection{Kinetic of adsorption}

See Supplementary Material [22].

\subsubsection{Equilibrium of adsorption}

See Supplementary Material [22].

\section{Results and discussion}

\subsection{Adsorbent characterisation}

\subsubsection{Isotherms of nitrogen and textural properties}

The $\mathrm{N}_{2}$ adsorption-desorption isotherms of both CSW and CSW-T are shown in Fig. 2. The samples exhibit curves closer to type III of pore models, meaning that there is no identifiable monolayer formation, according to IUPAC [23]. This isotherm suggests that the interactions

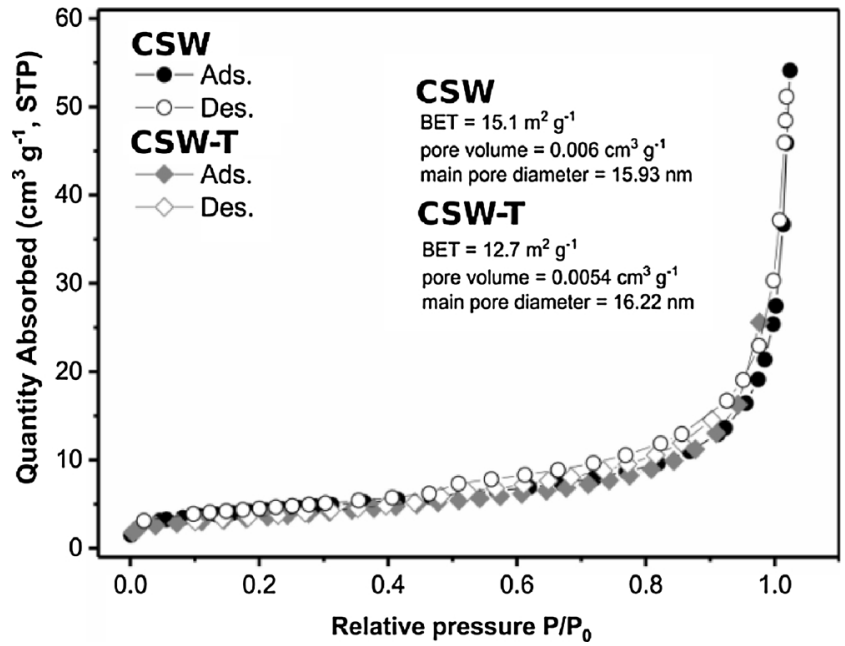

Fig. 2. $\mathrm{N}_{2}$ adsorption-desorption isotherms and porosity data of both CSW and CSW-T adsorbents.

between adsorbent and adsorbate are now relatively weak, and the adsorbed molecules are clustered around the most favourable sites on the surface of macroporous solid [23].

Since the diagonal length of a phosphate ion measures approximately $2.51 \AA$ calculated by using the Marvin Space 19.20.0. Also considering that micropores are pores with a diameter higher than $50 \mathrm{~nm}(500 \AA)$ [20], it is expected that micropores can adsorb several phosphate ions [24].

Concerning the $\mathrm{S}_{\mathrm{BET}}$, both CSW and CSW-T presented small values of area (15.1 and $12.7 \mathrm{~m}^{2} \mathrm{~g}^{-1}$ for CSW and CSW-T, respectively). The heating process promoted a little shrinkage in the CSW-T sample. The shrinkage can play an essential role in the quality of the adsorbent (in terms of phosphate adsorption). The heating process can provoke vital changes over the physical and chemical properties of the CWS-T; the changes in the body of the inorganic CSW might occur due to the overlap of a number of processes and phenomena associated with the decomposition of some of the biodegradable components such as small content of organic carbon (that usually is present in this kind of waste [1]) and calcium carbonates. Therefore, this might influence phosphate adsorption.

A good porosity favours a rapid inter-diffusion of the phosphate ions through interconnected and pores - channels; however, the low porosity of both adsorbents CSW and CSW-T indicates that chemical adsorption through functional surface groups could play an essential role in the adsorption of phosphate $[4,25]$.

\subsubsection{Chemical composition of the CSW adsorbents}

XRF determined the chemical composition of CSW and CSW-T. The results are shown in Table 1 . The CSW adsorbents are mainly formed by $\mathrm{SiO}_{2}, \mathrm{Al}_{2} \mathrm{O}_{3}$ and $\mathrm{CaO}$ and ferric oxide with small amounts of $\mathrm{MgO}, \mathrm{K}_{2} \mathrm{O}$,

Table 1

The chemical composition of the CSW and CSW-T expressed in their oxides.

\begin{tabular}{lll}
\hline Oxides & CSW (\%) & CSW-T (\%) \\
\hline $\mathrm{SiO}_{2}$ & 40.55 & 44.60 \\
$\mathrm{Al}_{2} \mathbf{O}_{3}$ & 12.90 & 18.20 \\
$\mathrm{CaO}$ & 10.17 & 10.10 \\
$\mathrm{Fe}_{2} \mathbf{O}_{3}$ & 4.02 & 9.60 \\
$\mathrm{~K}_{2} \mathbf{O}$ & 2.57 & 3.70 \\
$\mathbf{M g O}$ & 1.80 & 3.60 \\
$\mathrm{Na}_{2} \mathbf{O}$ & 1.20 & 1.60 \\
$\mathrm{SO}_{3}$ & 2.58 & 3.60 \\
$\mathrm{TiO}_{2}$ & 0.44 & 1.00 \\
$\mathbf{P}_{2} \mathbf{O}_{5}$ & 0.10 & - \\
\hline
\end{tabular}




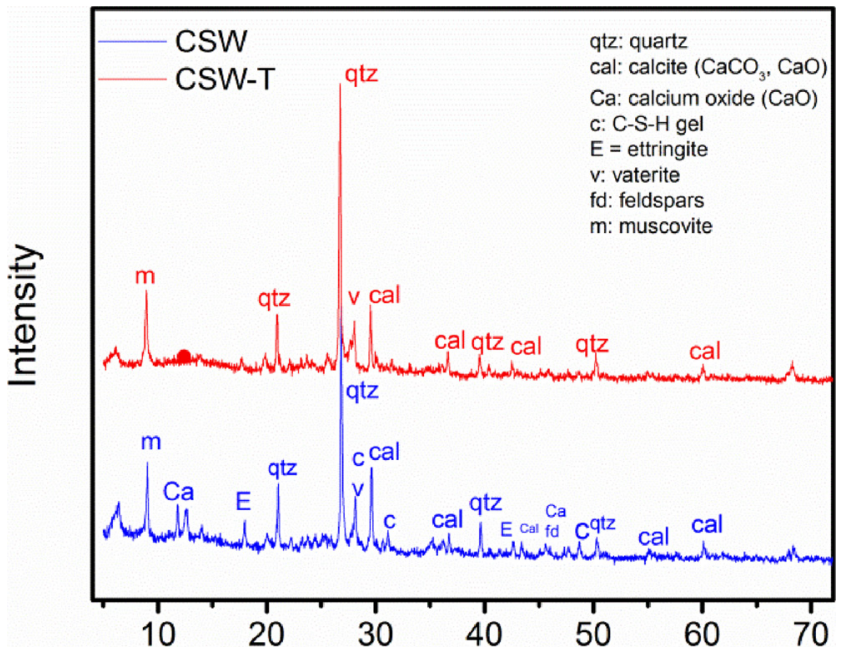

Fig. 3. XRD patterns of the CSW and CSW-T adsorbents.

$\mathrm{P}_{2} \mathrm{O}_{5}$, and $\mathrm{TiO}_{2}$ (see Table 1 ). As can be seen in Table 1 , the thermally treated sample exhibits higher oxides contents. The heating process provokes the decomposition of some of the biodegradable components such as calcium carbonates and small amounts of organic carbon and thus increase the proportion of oxides that remain stables at $800{ }^{\circ} \mathrm{C}$. It is reported that the immobilisation method using $\mathrm{Fe} / \mathrm{Mn} / \mathrm{Al}$ oxides or calcium (Ca)-bearing amendments is an efficient technique for the uptake and inhibit the mobilities of the ions in water environments $[26,27]$. These oxides could enhance the phosphate uptake and recovery it from aqueous solution.

\subsubsection{XRD characterisation of the CSW adsorbents}

After knowing the chemical composition of material using XRF, it is crucial to verify the identification of mineralogical composition. In this sense, XRD allows accurate information regarding the mineralogical composition of the CSW adsorbents. Fig. 3 shows the typical XRD patterns of the CSW adsorbents. According to the graphs, there are some differences in the XRD patterns of the CSW and CSW-T. Comparing the XRD patterns, it is possible to observe that the intensity in the crystallinity peaks was a little higher in thermally treated sample CSW-T. Also, some peaks disappeared after thermal treatment (see region around 10-20 theta and 40-50 theta) which was due to the loss of carbonates and C-H-S that are decomposed between $550-800{ }^{\circ} \mathrm{C}$. The loss of contents in CSW-T could reflect in different adsorption properties.

According to Fig. 3, the mineralogy properties of CSW adsorbents indicate the presence of a crystalline phase composed by quartz $\left(\mathrm{SiO}_{2}\right)$, calcite $\left(\mathrm{CaCO}_{3}\right)$, muscovite $\left[(\mathrm{KF})_{2}\left(\mathrm{Al}_{2} \mathrm{O}_{3}\right) 3\left(\mathrm{SiO}_{2}\right) 6\left(\mathrm{H}_{2} \mathrm{O}\right)\right]$ and calcium oxide $\left(\mathrm{CaO}, \mathrm{Ca}\left(\mathrm{OH}_{2}\right)\right)$ mainly, among others [4]. The presence of these elements are in concordance with XRF results (see Table 2). The presence of muscovite $\left(\mathrm{KAl}_{2}\left(\mathrm{Si}_{3} \mathrm{AlO}_{10}\right)(\mathrm{OH})_{2}\right)$ was also identified in both samples (Fig. 3). Muscovite comes from cement/mortar [4,26,27]. The calcite is formed via the natural carbonation of lime $(\mathrm{CaO})$ with atmospheric $\mathrm{CO}_{2}[4,26,27]$.

Table 2

Effect of $\mathrm{pH}$ in the $\mathrm{P}$ removal and in the $\mathrm{Ca}^{2+}$ dissolved.

\begin{tabular}{lll}
\hline $\mathrm{pH}$ & $\mathrm{q}\left(\mathrm{mg} . \mathrm{g}^{-1}\right)$ & {$\left[\mathrm{Ca}^{2+}\right]\left(\mathrm{mg} . \mathrm{L}^{-1}\right)$} \\
\hline 2.0 & 5.1 & 489.1 \\
3.2 & 7.4 & 425.2 \\
5.0 & 12.1 & 156.3 \\
7.1 & 21.9 & 41.0 \\
9.4 & 38.7 & 18.1 \\
11.2 & 35.0 & 5.2 \\
\hline
\end{tabular}
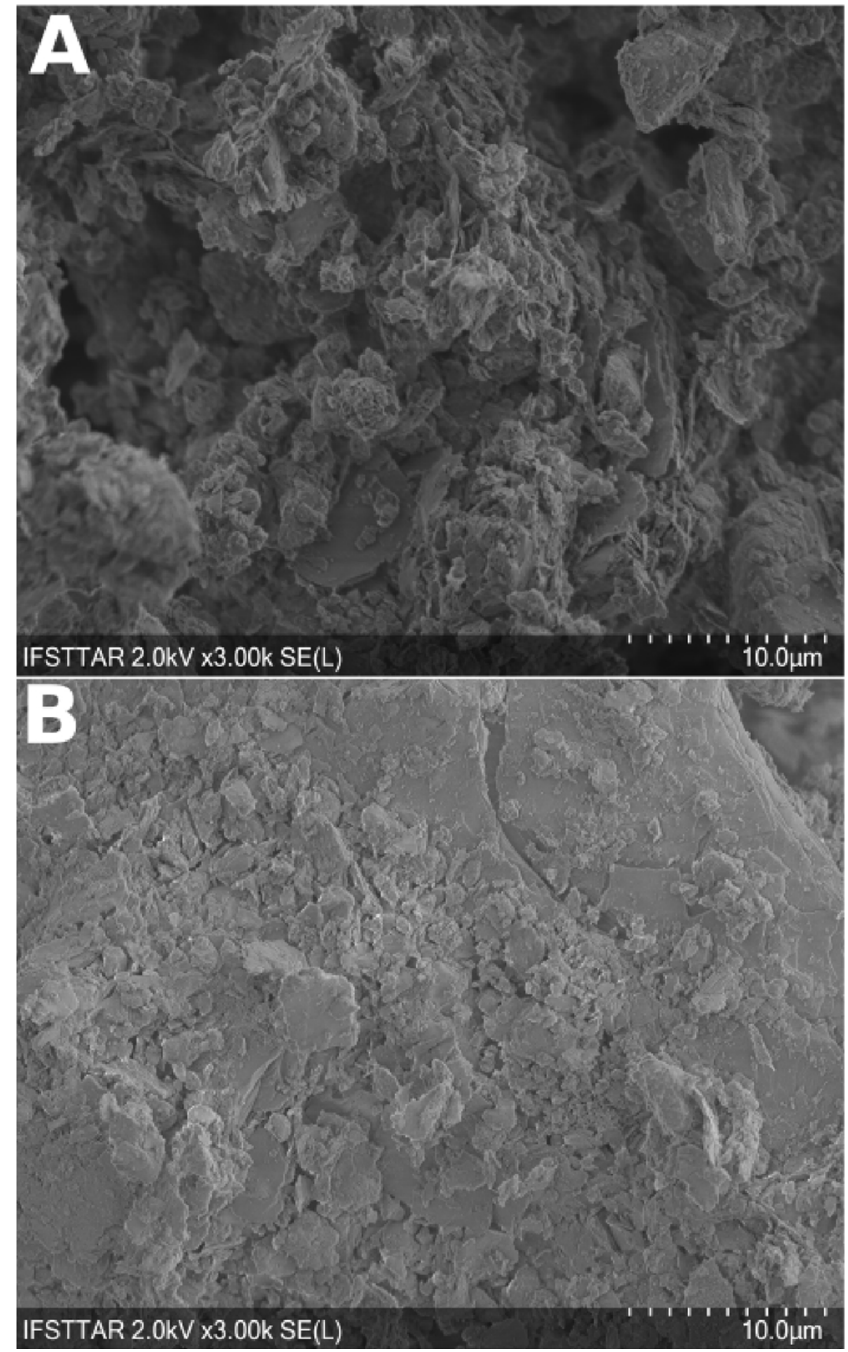

Fig. 4. SEM images of CSW (A), and CSW-T (B).

The chemical composition of CSW support its reuses as adsorbents due to the fact of the presence of many inorganic oxides can improve the adsorption performance of the solid waste $[4,26,27]$.

\subsubsection{SEM of the CSW adsorbents}

Scanning electron microscopy (SEM) is one of the main techniques for material characterisation due to its ability to provide morphological and structural details of the studied material. Fig. 4 shows the SEM microstructures of CSW and CSW-T adsorbents. The images reveal differences between both microstructures. CSW displayed disordered agglomeration of very fine particles and some layered structures (See Fig. 4).

Fig. 4B shows the SEM for CSW-T, its microstructure shows more cohesive, regular and enlongeted shape, probably due to the crystallization and vitrification of some elements such as calcium, carbonate, and other compounds derived from cement, as mentioned in the XRD analysis. The differences between CSW and CSW-T morphologies might reflect on their adsorption properties.

\subsection{Adsorption studies}

\subsubsection{Effect of adsorbent mass}

The amount of mass adsorbent is a crucial factor for industrial-scale application aiming to obtain the best efficiency removal of the desired pollutant. Also, the effect of adsorbent mass is substantial because it avoids minimising costs involved with the adsorption [25,28]. 

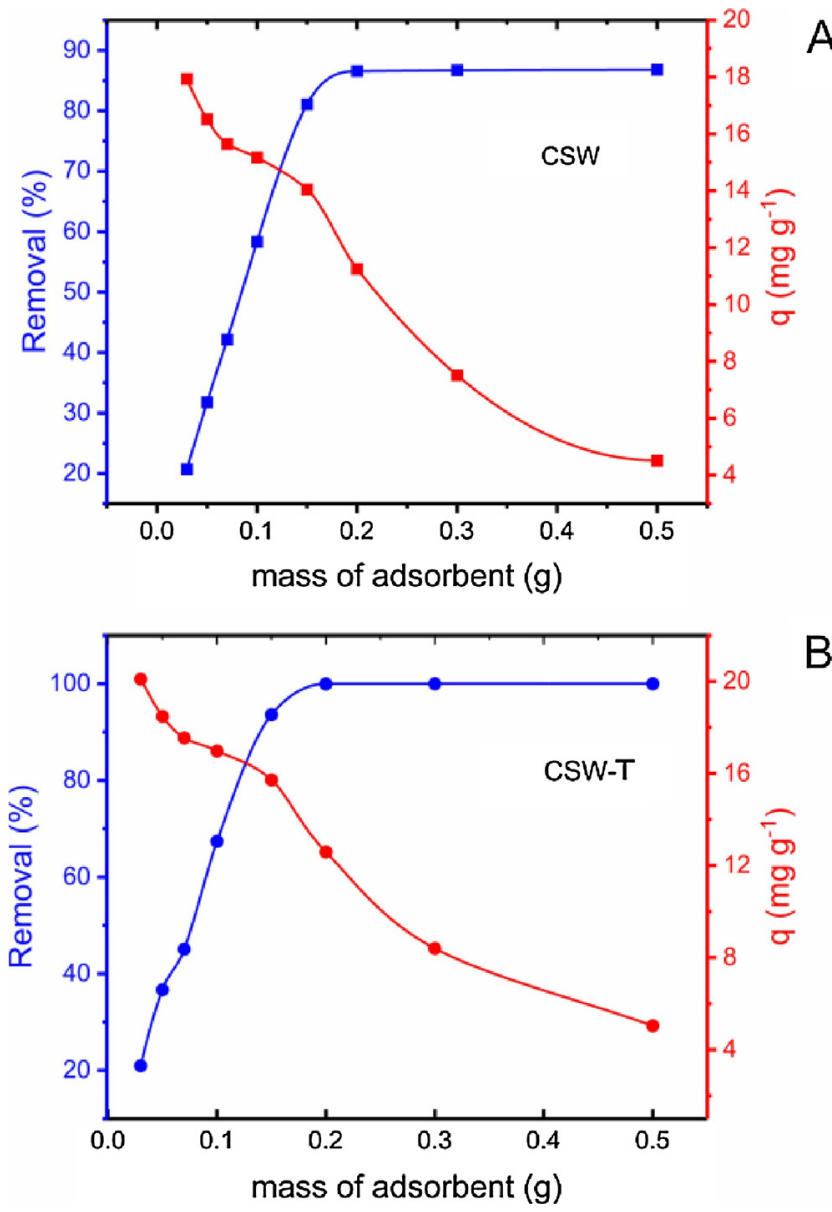

Fig. 5. Effect of adsorbent dosage on P removal. CSW (A), and CSW-T (B).

The effect of mass adsorbent addition on the phosphate removal over CSW and CSW-T adsorbent was carried out using quantities of ranging from 0.030 to $0.500 \mathrm{~g}$ with a fixed volume of $20.0 \mathrm{~mL}$ of $\mathrm{P}$ solution at the initial concentration of $130.0 \mathrm{mg} \mathrm{L}^{-1}$. The best adsorption result for phosphate was attained using $0.150 \mathrm{~g}$ of both adsorbents obtaining $81.06 \%$ (CWS), and $99.95 \%$ (CSW-T) of P removal, that corresponds to sorption capacity of $14.1(\mathrm{CSW})$, and $15.7 \mathrm{mg} \mathrm{g}^{-1}$ (CSWT) (see Fig. 5).

The rapid enhance in the removal of phosphate as the dosage of adsorbent increases suggests the accessibility of a higher number of available adsorption sites for a higher adsorbent dosage that enables adsorbing more considerable amount of phosphate ions (see Fig. 5). This means that a large number of free adsorption sites were available to adsorb P species during the first stage of the adsorption process and then, with the progressing of the time, the free remaining adsorption sites were less and then difficulting to be occupied by the phosphate ions due to repulsive forces between the adsorbent and adsorbate $[25,28]$.

About the adsorption capacity, the increase of the adsorbent dosage led to an increase of the exposed area and therefore the adsorption increases; however, due to the fact the initial concentration of phosphate ions do not change and that the quantity adsorbed does not increase proportionally (linearly) with the increase of the CSW-T dosage, the adsorption capacity (mg of Phosphate / g of CSW-T) decreases. When both CSW-T and phosphate ions from solution come in contact, the adsorption process rapidly takes place in high rates. Afterwards, as the phosphate ions concentration decline, the remaining phosphate ions in the solution diffuse more slowly and thus, the adsorption is reduced.

Based on these results, for the next adsorption experiments, including $\mathrm{pH}$ and temperature effects, kinetic and isotherms experiments, a mass of $0.15 \mathrm{~g}$ was selected.

\subsubsection{Effect of the $\mathrm{pH}$ on phosphate removal}

The $\mathrm{pH}$ is a fundamental parameter in the process of adsorption in solution because it determines the load of the adsorbent surface and governs the electrostatic interactions between the adsorbent and the adsorbate.

Several phosphorus species (in terms of phosphates, $\mathrm{H}_{3} \mathrm{PO}_{4}$, $\mathrm{H}_{2} \mathrm{PO}_{4}{ }^{-}, \mathrm{HPO}_{4}{ }^{2-}$ and $\mathrm{PO}_{4}{ }^{3-}$ ) can be present in the solution, and their proportions depend on $\mathrm{pH}$ solution [29]. Based on the $\mathrm{pH}$ results on phosphate removal, the trend shows an increase in $\mathrm{P}$ removal with increasing $\mathrm{pH}$ to the lowest capacity at $\mathrm{pH} 2.0$ and the highest at $\mathrm{pH} 9.4$ (see Table 2).

This could be explained by the fact that the phosphorus adsorption is linked to the $\mathrm{Ca}^{2+}$ ions dissolution from the adsorbent, which reacts with the $\mathrm{P}$ species present in the solution [29]. The presence of phosphorus species, depending on the $\mathrm{pH}$ values of the solution [30]. When $\mathrm{pH}$ value is about $9.4, \mathrm{HPO}_{4}{ }^{2-}$ is the dominant specie in the solution [30]. According to Yan et al. [31], the precipitation of calcium phosphate is the predominant mechanism in phosphorus immobilisation at higher $\mathrm{pH}$ value. This immobilisation takes place by the dissolution of $\mathrm{Ca}^{2+}$ from the CSW adsorbent, and $\mathrm{Ca}^{2+}$ reacts with $\mathrm{HPO}_{4}{ }^{2-}$, for instance, to form calcium phosphate [30,31].

It related to the literature that the concentration of dissolved $\mathrm{Ca}^{2+}$ decreases when the initial $\mathrm{pH}$ value increases, which causes the inhibition of calcium phosphate precipitation and thus diminishes $\mathrm{P}$ adsorption $[30,31]$. This trend was observed in this work, as shown in Table 2.

The decrease of $\mathrm{pH}$ solution could also help the CSW release more $\mathrm{Ca}^{2+}$ ions into the solution. However, the species of phosphate will form $\mathrm{H}_{3} \mathrm{PO}_{4}$ inhibiting its precipitation with calcium [29-31]. However, at $\mathrm{pH} 11.2$ values the concentration of $\mathrm{Ca}^{2+}$ released is drastically decreased, and the uptake of $\mathrm{P}$ species by the adsorbent is also diminished. (see Table 2). As a balance of letting $\mathrm{P}$ as an anion, and also having a good level of $\mathrm{Ca}^{2+}$, further experiments were carried out at $\mathrm{pH}$ 8.0.

$3 \mathrm{HPO}_{4^{2-}}+2 \mathrm{C}_{\mathrm{a}^{2+}} \stackrel{\mathrm{pH} 8.0}{\rightleftharpoons} \mathrm{ca}_{2}\left(\mathrm{PO}_{4}\right)_{3(\mathrm{~s})}+3 \mathrm{H}^{+}$

\subsubsection{Effect of the temperature on $P$ removal}

In adsorption processes, the effect of temperature on the system can affect the adsorption rate by increasing the kinetic energy and the mobility of adsorbable species and also can cause an increase in the intraparticle-diffusion rate of the adsorbates.

Fig. 6 shows the influence of temperature on phosphate adsorption onto CSW and CSW-T adsorbents. The adsorption capacity of phosphate for CSW-T increased from 33.1 to $40.4 \mathrm{mg} \mathrm{g}^{-1}$ with an increase in temperature from $22^{\circ} \mathrm{C}$ to $50{ }^{\circ} \mathrm{C}$ (an increase in sorption capacity in the order of $22.1 \%$ from $22^{\circ}$ to $50^{\circ} \mathrm{C}$ ). The same behaviour was also observed for CSW, which the "q" increased from 21.3 to $33.5 \mathrm{mg} . \mathrm{g}^{-1}$ while the temperature increased from $22^{\circ} \mathrm{C}$ to $50{ }^{\circ} \mathrm{C}$ (an increase of $57.3 \%$ in sorption capacity). The effect of the temperature on sorption capacity was more remarkable for CSW (57.3\%) than CSW-T adsorbent (22.1\%). The effect of the temperature for phosphate adsorption was also observed in the literature [31-33].

Even the temperature is an important variable which improved the adsorption of phosphorus in $22.1 \%$ at $50{ }^{\circ} \mathrm{C}$, this temperature increase results in a very high operational cost of the process which it is not always justified, therefore, $22^{\circ} \mathrm{C}$ was chosen to be the temperature for the next experiments.

\subsubsection{Kinetic study of the adsorption}

Knowing the kinetics of adsorption of a system is a decisive factor for designing a high-efficiency adsorption process. Kinetic analysis provides insights about the interaction between the adsorbent and 


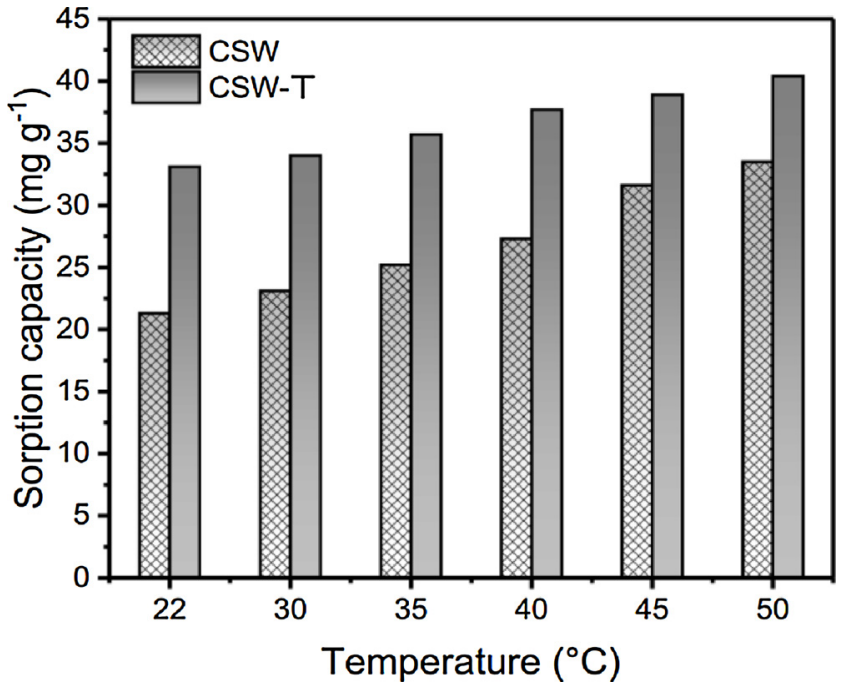

Fig. 6. Effects of temperature on phosphate P adsorption onto CSW and CSW-T adsorbents.

adsorbate. Also, the kinetic study is essential because of furnish information about the adsorption equilibrium and mechanism.

The kinetic adsorption evaluation of phosphate P onto CSW and CSW-T was performed to establish its optimal time for adsorption. Making numerical interpolation in the best kinetic fitted curve, the results show that the adsorption process is really speedy in the beginning, for CSW adsorbent $70 \%$ of the $\mathrm{P}$ was adsorbed in $8.79 \mathrm{~min}$ and for CSW-T 70\% of P was adsorbed in $3.34 \mathrm{~min}$ (see Fig. 7), and then the phosphate was slowly adsorbed onto the reaching $95 \%$ of removal at around 212.6, and $136.6 \mathrm{~min}$ for CSW, and CSW-T, respectively. Remarkably, the kinetics of adsorption of phosphate P onto CSW-T is much faster when compared with CSW. The thermal treatment improved the adsorption properties, probably, the small content of volatile and organic matters are degraded by the heating process, and this could enhance the adsorption properties of the CSW-T. Also, the amount of oxides are higher in CSW-S (see Table 1), and this could improve its adsorption properties [4,34-39]. These behaviours for the phosphate $\mathrm{P}$ adsorption have been observed in prior researches on phosphate removal by using different adsorbents based on iron oxides [4,34-39].

These results indicate that for both adsorbents, there are a significant number of adsorption sites available to be filled which results in the speedy adsorption process, due to the high driving force in the mass transfer $[28,39,40]$. The adsorption rate of P onto CSW and CSW-T are fast, probably resulting from the significant presence of many functional groups and oxides that are effectively involved in the phosphate capture $[28,38-40]$.

About the kinetic models, three models, pseudo-first-order, pseudosecond-order and Avrami models were used to fit the experimental data [22]. The fitting parameters are exhibited in Table 3. It illustrates that the kinetic data is more suitable to characterise with the Avrami-fractional-order model. It has to be mentioned here, that these models are used as lumped kinetic approaches here, in regards that the whole adsorption process is more complicated than a single-step mechanism [41]. It is mentioned before, that there is likely a relative strong ionic bonding of phosphate on the surface, which makes the assumption of irreversible adsorption suitable, which is necessary for the original pseudo-first or pseudo-second-order approach. On the other hand and at higher loading, it is mentioned above that the ions may interact with each other, which contradict the original set of approximations for these models. Notwithstanding, as a lumped approach, it might be useful at all.

The suitability of the kinetic models was evaluated according to the
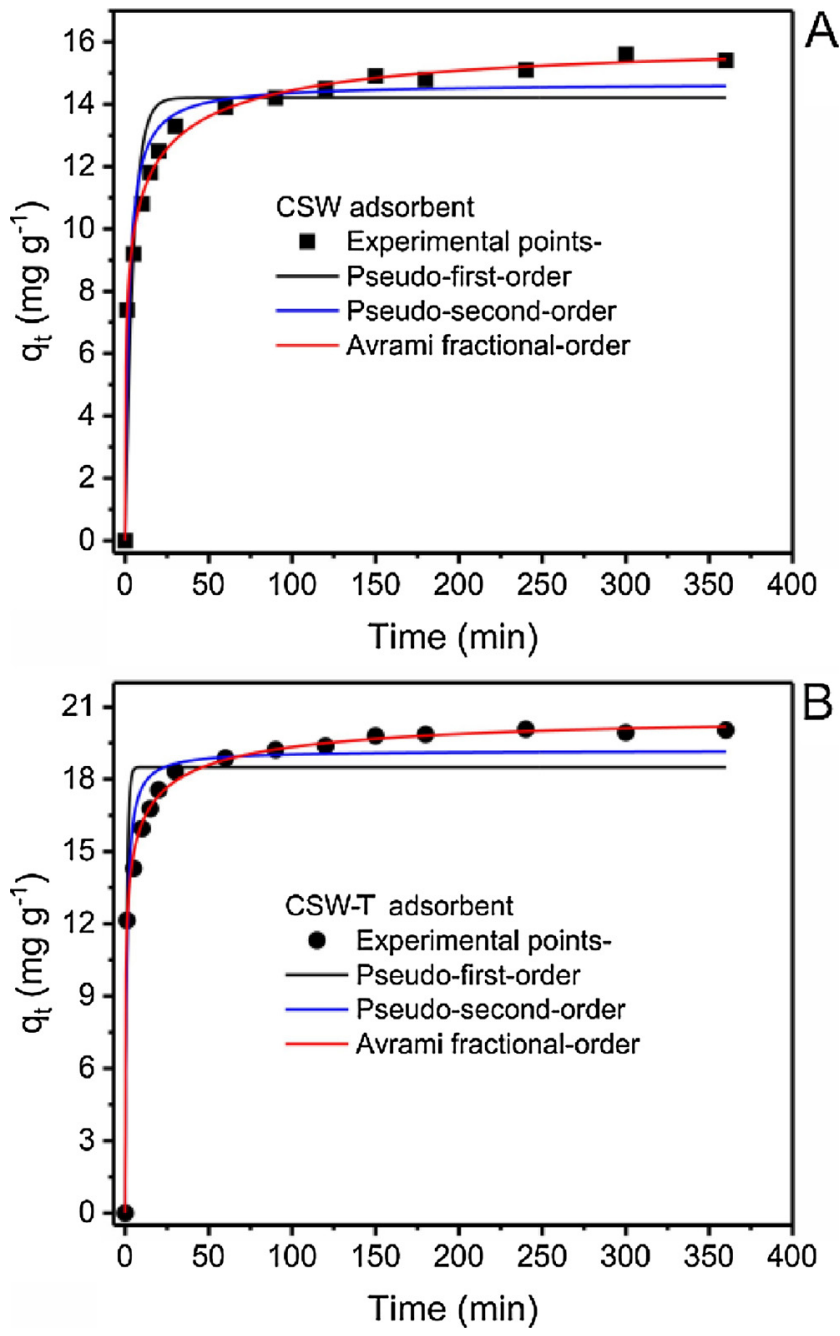

Fig. 7. Kinetic curves for adsorption of P (A) CSW and (B) CSW-T.

Table 3

Parameters of the kinetic of Pseudo-First-Order, Pseudo-Second-Order and Avrami-Fractional-Order models for the adsorption of P onto CSW and CSW-T. Conditions: initial $\mathrm{pH}$ of $\mathrm{P}$ solution 8.0; the adsorbent mass of $0.1000 \mathrm{~g}$.

\begin{tabular}{|c|c|c|}
\hline Adsorbent & CSW & CSW-T \\
\hline \multicolumn{3}{|l|}{ Pseudo-First-Order } \\
\hline$q_{e}\left(\mathrm{mg} \mathrm{g}^{-1}\right)$ & 14.21 & 18.50 \\
\hline$k_{1}\left(\min ^{-1}\right)$ & 0.2117 & 1.013 \\
\hline $\mathrm{t}_{1 / 2}(\min )$ & 3.274 & 0.6842 \\
\hline $\mathrm{t}_{0.95}(\mathrm{~min})$ & 14.15 & 2.957 \\
\hline$R_{\text {adj }}^{2}$ & 0.8373 & 0.8894 \\
\hline$S D\left(\mathrm{mg} \mathrm{g}^{-1}\right)$ & 1.673 & 1.733 \\
\hline \multicolumn{3}{|c|}{ Pseudo-Second-Order } \\
\hline$q_{e}\left(\mathrm{mg} \mathrm{g}^{-1}\right)$ & 14.67 & 19.19 \\
\hline$k_{2}\left(\mathrm{~g} \mathrm{mg}^{-1} \min ^{-1}\right)$ & 0.03176 & 0.05953 \\
\hline$t_{1 / 2}(\min )$ & 2.147 & 0.8753 \\
\hline $\mathrm{t}_{0.95}(\mathrm{~min})$ & 40.79 & 16.63 \\
\hline$R_{a d j}^{2}$ & 0.9353 & 0.9523 \\
\hline$S D\left(\mathrm{mg} \mathrm{g}^{-1}\right)$ & 1.055 & 1.138 \\
\hline \multicolumn{3}{|c|}{ Avrami-Fractional-Order } \\
\hline $\mathrm{q}_{\mathrm{e}}\left(\mathrm{mg} \mathrm{g}^{-1}\right)$ & 15.92 & 20.63 \\
\hline $\mathrm{k}_{\mathrm{AV}}\left(\min ^{-1}\right)$ & 0.1735 & 0.5253 \\
\hline $\mathrm{n}_{\mathrm{AV}}$ & 0.3041 & 0.2568 \\
\hline $\mathrm{t}_{1 / 2}(\min )$ & 1.727 & 0.4568 \\
\hline $\mathrm{t}_{0.95}(\mathrm{~min})$ & 212.6 & 136.6 \\
\hline $\mathrm{R}^{2}$ adjusted & 0.9953 & 0.9974 \\
\hline $\mathrm{SD}\left(\mathrm{mg} \mathrm{g}^{-1}\right)$ & 0.2838 & 0.2657 \\
\hline
\end{tabular}


adjusted determination coefficient $\left(\mathrm{R}_{\mathrm{adj}}^{2}\right)$, and standard deviation of residues (SD), meaning that lower $S D$ and higher $R_{\text {adj }}^{2}$ values imply a smaller difference between theoretical and experimental $\mathrm{q}$ values (which is given by the models).

In this matter, according to the kinetic data displayed in Table 3, the Avrami kinetic model was the most suitable model which best represent the experimental kinetic data, since it presented lower SD $(0.2838$ and 0.2627 ) and higher $R_{\text {adj }}^{2}$ values (0.9953 and 0.9974), for both CSW and CSW-T, respectively (see Table 3). This indicates that the $\mathrm{q}_{\mathrm{t}}$ predicted by the Avrami kinetic model presented the closest calculated values (from the model) to the experimental $\mathrm{q}_{\mathrm{t}}$.

Avrami's model assumes that the system subjected to the mechanism change and the better fitting with Avrami model suggests that the phosphate removal on both adsorbents, CSW and CSW-T, have different adsorption mechanisms, which might be associated with the chemical adsorption as well with the formation of precipitates with phosphate.

\subsubsection{Equilibrium models}

In this work, the adsorption behaviours between the phosphate species and the CSW adsorbents are described by using the equilibrium isotherm models. Among several isotherm models described in the literature, were chosen Langmuir, Freundlich and Liu isotherms to evaluate the fitness of the equilibrium data of phosphate onto CSW adsorbents.

The adsorption equilibrium isotherms of phosphate $\mathrm{P}$ onto both CSW and CSW-T at $22^{\circ} \mathrm{C}$ are displayed in Fig. 8. Also, Table 4 displays equilibrium parameters for the selected isotherm models.

As can be seen in Table 4, in addition to presenting the parameters of isotherm models, the goodness of fit of experimental equilibrium data with Langmuir, Freundlich and Liu isotherms was evaluated using the $R_{A d j}^{2}$, and $S D$ similar to the kinetic studies discussed above.

In the light of $R_{A d j}^{2}$ and $S D$ values, the isothermal adsorption process is more suitable to be described with Liu model, because it is the highest $R_{A d j}^{2}$ and the lowest $S D$ values, in comparison with Langmuir and Freundlich models. This finding means that Langmuir and Freundlich's isotherms show lower goodness of fit, since they have lower $\mathrm{R}_{\mathrm{Adj}}^{2}$ and higher values of SD for both adsorbents (CSW and CSW-T), meaning that these models do not offer a reasonable description of the process. Likewise, the $q$ values provided by the Liu model were closer to those obtained experimentally.

This is not surprising. The Langmuir model based on the assumption that only a mono-layer will be formed, hereby the bonding of phosphates on the mineral sides of the CSW materials. Here, hints were mentioned that besides precipitation occurs, which can not described by the Langmuir model. The Freundlich model includes the formation of multilayers before the first layer is complete. It does not take into account the strong bonding of the first layer in the system here. Therefore the Freundlich model under predicts the adsorption at low $\mathrm{C}_{\mathrm{e}}$ and overpredicts it at high $\mathrm{C}_{\mathrm{e}}$ (see Fig. 8).

Liu model assumes that the adsorption of phosphate onto CSW and CSW-T adsorbents is heterogeneous by the existence of different active sites acting simultaneously and with different free adsorption energies. However, a saturation of the adsorbent takes place, attaining a maximum sorption capacity $\left(\mathrm{Q}_{\max }\right)$.

The maximum adsorption capacities of phosphate $\mathrm{P}$ onto CSW and CSW-T were 24.04 and $57.64 \mathrm{mg} \mathrm{g}^{-1}$, respectively, at $22^{\circ} \mathrm{C}$, according to Liu isotherm. The surface features and chemical composition of the adsorbents can explain the differences in the $\mathrm{Q}_{\max }$ values. The literature highlights that the presence of carbonate can inhibit the activity of $\mathrm{Ca}^{2+}$, thus weakening the phosphate removal performance [42]. Zhang et al. [43], studied the effect of carbonates on the phosphate adsorption on $\mathrm{Ca}(\mathrm{OH})_{2}$ and concluded that the phosphate removal was strongly inhibited by the presence of carbonates. The presence of carbonates is expected in CSW since this waste is mainly composed of concrete, cement and recycled aggregates materials. Also, the XRD analysis
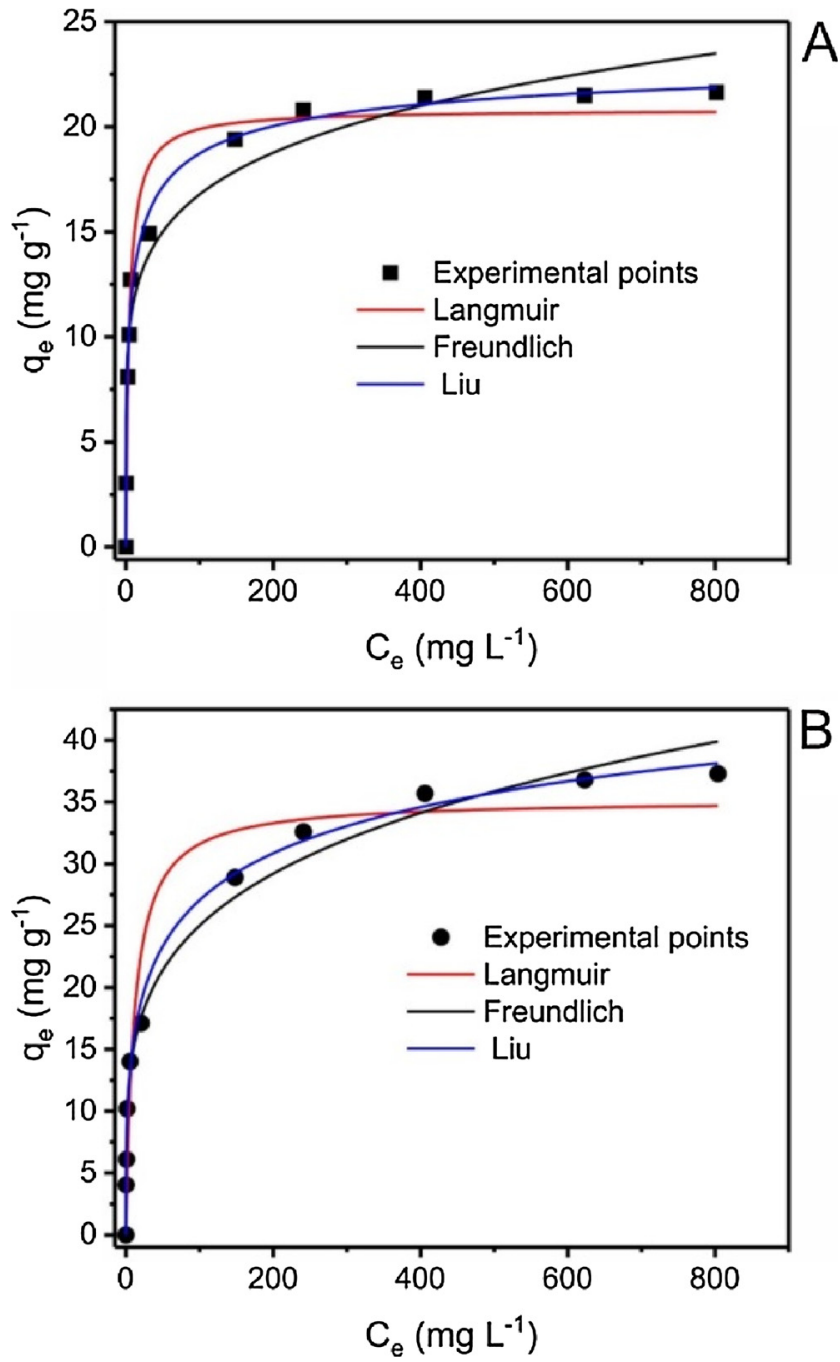

Fig. 8. Adsorption isotherm profiles of $\mathrm{P}$ for (A) CSW and (B) CSW-T.

Table 4

Parameters of the isotherm of Langmuir. Freundlich and Liu models for the adsorption of P onto CSW and CSW-T. Conditions: initial pH of P solution 8.0; the Adsorbent mass of $0.1000 \mathrm{~g}$; contact time of $5 \mathrm{~h}$; temperature of $22^{\circ} \mathrm{C}$.

\begin{tabular}{lll}
\hline Adsorbent & CSW & CSW-T \\
\hline Langmuir & & \\
$Q_{\max }\left(\mathrm{mg} \mathrm{g}^{-1}\right)$ & 20.82 & 35.18 \\
$K_{L}\left(\mathrm{~L} \mathrm{mg}^{-1}\right)$ & 0.2149 & 0.08816 \\
$R_{\text {adj }}^{2}$ & 0.9653 & 0.9289 \\
$S D\left(\mathrm{mg} \mathrm{g}^{-1}\right)$ & 1.459 & 3.820 \\
Freundlich & & \\
$K_{F}\left(\mathrm{mg} \mathrm{g}^{-1}\left(\mathrm{mg} \mathrm{L}^{-1}\right)^{-1 / \mathrm{nF}}\right)$ & 7.971 & 8.902 \\
$n_{F}$ & 6.187 & 4.460 \\
$R_{\text {adj }}^{2}$ & 0.9551 & 0.9846 \\
$S D\left(\mathrm{mg} \mathrm{g}^{-1}\right)$ & 1.660 & 1.780 \\
$\mathrm{Liu}_{Q_{\max }\left(\mathrm{mg} \mathrm{g}^{-1}\right)}$ & \\
$K_{g}\left(\mathrm{~L} \mathrm{mg}^{-1}\right)$ & 24.04 & 57.64 \\
$n_{L}$ & 0.1224 & 0.007258 \\
$R_{\text {adj }}^{2}$ & 0.5033 & 0.3806 \\
$S D\left(\mathrm{mg} \mathrm{g}^{-1}\right)$ & 0.9926 & 0.9940 \\
& 0.6736 & 1.108 \\
\hline
\end{tabular}

highlighted the presence of carbonates in CSW. However, in CSW-T, its presence is expected to diminish since It is well known that the carbonates are decomposed around $600-800^{\circ} \mathrm{C}$ [44], and CSW-T was heated at $800^{\circ} \mathrm{C}$. More details about the differences in the $\mathrm{Q}_{\max }$ will be more discussed in the adsorption mechanism (coming section). 
Table 5

Comparison of adsorption capacities of different adsorbents for acetaminophen.

\begin{tabular}{|c|c|c|c|c|}
\hline Adsorbent & $\mathrm{Q}_{\max }\left(\mathrm{mg} \mathrm{g}^{-1}\right)$ & Isotherm model & Conditions & Ref. \\
\hline synthesized magnetite & $15.2^{*}$ & Frendlich & $1.0 \mathrm{~g}$ of adsorbent in $20 \mathrm{~mL}$ of solution; $2 \mathrm{~h} ; 22 \mathrm{C}$; $\mathrm{pH}$ of 5.0 & [25] \\
\hline calcined waste eggshell & $22.3^{*}$ & Frendlich & $0.7 \mathrm{~g}$ of adsorbent in $50 \mathrm{~mL}$ of solution ; $72 \mathrm{~h} ; 22 \mathrm{C} ; \mathrm{pH}>4.0 ; 200 \mathrm{rpm}$ & [29] \\
\hline Recycled concrete & 6.88 & Langmuir & $\mathrm{pH}$ of 5.0 ; zise particles $2-5 \mathrm{~mm} ; 2.0 \mathrm{~g}$ of adsorbent in $100 \mathrm{~mL}$ of solution; & {$[30]$} \\
\hline Alum sludge & 6.06 & Langmuir & & [32] \\
\hline Burnt Crushed Concrete Granules (700C) & 21.55 & Langmuir & $\mathrm{pH}$ 7.0; Equilibrium time of $30 \mathrm{~min}$; Adsorbent dosage of $5 \mathrm{~g} / \mathrm{L}$ & [33] \\
\hline Burnt Crushed Concrete Granules (900C) & 8.47 & Langmuir & $\mathrm{pH}$ 7.0; Equilibrium time of $30 \mathrm{~min}$; Adsorbent dosage of $5 \mathrm{~g} / \mathrm{L}$ & [33] \\
\hline acid-modified fly ash & 13.3 & Langmuir & $\mathrm{pH}$ ranging 3 to $\sim 5$; $25 \mathrm{C}$; Equilibrium time of $60 \mathrm{~min}$ & [34] \\
\hline palygorskite & 10.5 & Langmuir & $\mathrm{pH}$ ranging 3 to $\sim 5$; $25 \mathrm{C}$; Equilibrium time of $60 \mathrm{~min}$ & [34] \\
\hline iron oxide/AC & 98.39 & Langmuir & $\mathrm{pH}$ of 3.0 ; Adsorbent dosage of $0.8 \mathrm{~g} / \mathrm{L} ; 60 \mathrm{~min}$ & [35] \\
\hline AC & 78.90 & Langmuir & $\mathrm{pH}$ of 3.0; Adsorbent dosage of $0.8 \mathrm{~g} / \mathrm{L} ; 60 \mathrm{~min}$ & [35] \\
\hline CSW & 24.04 & Liu & & This work \\
\hline CSW-T & 57.64 & Liu & & This work \\
\hline
\end{tabular}

Obs: * Experimental value for $\mathrm{q}$.

\subsubsection{Adsorbent efficiency}

The adsorbent efficiency evaluation is usually made by comparing the $\mathrm{Q}_{\max }$ values predicted by the best-fitted isotherm model with those reported for other materials, for the same adsorbate. In this sense, Table 5 shows the $Q_{\max }$ values of some adsorbents towards the phosphate adsorption. The CSW and CSW-T adsorbents presented $\mathrm{Q}_{\max }$ values of 24.04 and $57.64 \mathrm{mg} \mathrm{g}^{-1}$, which correspond to the highest adsorption capacities among the cited adsorbents in Table 5. Therefore it is possible to infer that, based on Table 5, CSW and CSW-T adsorbents could be very efficient and cost-effective for phosphate adsorption and recovery from aqueous effluents since it is abundant and cheap to be enabled for adsorption experiments.

\subsubsection{Possible mechanisms of phosphate removal}

The adsorption of $\mathrm{P}$ species ions on the positively-charged surface of CSW and CSW-T and the precipitation of phosphate compounds can both respond for the P removal and recovery. The significance of each mechanism would probably be determined by $\mathrm{pH}$ of the adsorbate-adsorbent system, by the forms of oxides on the CSW surfaces and by the ionic species in the solution which is influenced by $\mathrm{pH}$ [35-39].

At $\mathrm{pH} 2.0$, the phosphorous is predominantly (58.4\%) $\mathrm{H}_{3} \mathrm{PO}_{4}$ and $\mathrm{H}_{2} \mathrm{PO}_{4}{ }^{-}$, which is present at $41.6 \%$ (see Fig. 9). The neutral specie $\left(\mathrm{H}_{3} \mathrm{PO}_{4}\right)$ could not be precipitated by $\mathrm{Ca}^{2+}$ forming $\mathrm{Ca}_{2}\left(\mathrm{PO}_{4}\right)_{3(\mathrm{~s})}$ at the surface of the adsorbent as it usually occurs with the anionic species of phosphate ions $\left(\mathrm{H}_{2} \mathrm{PO}_{4}-; \mathrm{HPO}_{4}{ }^{2-}\right.$; and $\mathrm{PO}_{4}{ }^{3-}$ ) (see Table 2). At $\mathrm{pH}$ values higher than $\mathrm{pK}_{1}(\mathrm{pH}>2.148)$ predominate the specie $\mathrm{H}_{2} \mathrm{PO}_{4}$-(see Fig. 9). At the $\mathrm{pH} 4.673$, the specie $\mathrm{H}_{2} \mathrm{PO}_{4^{-}}$presents its higher fraction

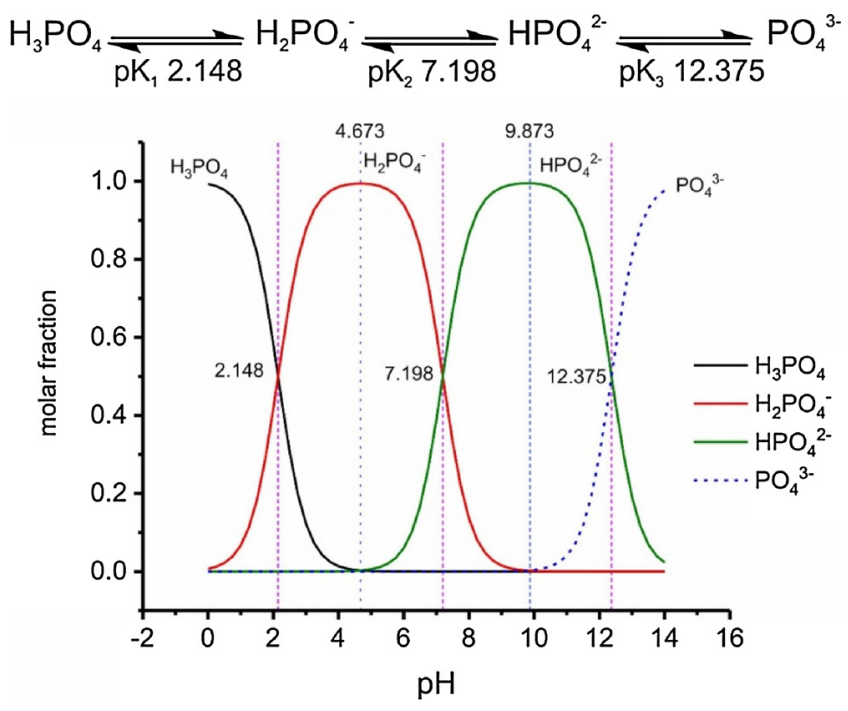

Fig. 9. Diagram speciation of phosphate ions.
(99.41\%), and the sorption capacity of CSW is higher about $\mathrm{pH} 2.0$. According to Table 2, the higher percentage of removal occurs when $\mathrm{pH}>9.4$, where it is the predominance of the specie $\mathrm{HPO}_{4}{ }^{2-}$ (see Fig. 9). The chemical reactions that occur are:

$$
\begin{gathered}
2 \mathrm{HPO}_{4}^{2-} \stackrel{\mathrm{K}_{\mathrm{a} 3}}{\rightleftharpoons} 2 \mathrm{PO}_{4}^{3-}+ \\
3 \mathrm{Ca}^{2+}+2 \mathrm{PO}_{4}^{3-} \underset{\mathrm{K}=1 / \mathrm{K}_{\mathrm{sp}}}{\rightleftharpoons} \mathrm{Ca}_{2}\left(\mathrm{PO}_{4}\right)_{3(\mathrm{~s})} \\
3 \mathrm{Ca}^{2+}+2 \mathrm{HPO}_{4}^{2-} \underset{\mathrm{K}=2.04 .10^{20}}{\rightleftharpoons} \mathrm{Ca}_{2}\left(\mathrm{PO}_{4}\right)_{3(\mathrm{~s})}
\end{gathered}
$$

Considering that $\mathrm{K}_{\mathrm{a} 3}$ of phosphoric acid is $4.22 .10^{-13}$ and that $\mathrm{K}_{\mathrm{sp}}$ of calcium phosphate is $2.07 .10^{-33}$, the equilibrium constant for the precipitation of $\mathrm{HPO}_{4}{ }^{2-}$ with $\mathrm{Ca}^{2+}$ will be $2.04 .10^{20}$. This high value of the equilibrium constant will generate a high negative value of Gibb's free energy, indicating that this chemical equilibrium lays forcefully on the side of the salt $\left(\Delta \mathrm{G}^{\circ}-115.9 \mathrm{~kJ} \mathrm{~mol}^{-1}\right)$.

Besides the possibility of forming calcium phosphate at the surface of CSW and CSW-T, phosphate species are also preferentially adsorbed by hydroxyl groups on the surface of oxides, which are mostly protonated below pH 7-9 [31]. Hydroxylation takes place when, for instance, Fe ions on mineral surfaces are exposed to water and complete its coordination with hydroxyl groups [34].

Adsorption of phosphate in CSWs can occur by functional groups (presents in $\mathrm{Fe}, \mathrm{Al}, \mathrm{Ca}$, oxides, for instance) which results in the formation of surface complexes [39]. These surface complexes are called "inner-sphere complexes" to indicate that they are strongly bonded to structure mineral surfaces via covalent binding [39] highly. The Fig. 10 shows the SEM and EDS mapping of the main elements found in CSW-T loaded $\mathrm{P}$. It shows that the main elements are $\mathrm{Fe}, \mathrm{Al}$, and $\mathrm{Ca}$ and the presence of $\mathrm{P}$ was also detected, highlighting that CSW-T adsorbed the $\mathrm{P}$ (as phosphate).

Deng and Wheatley [33] corroborated the same findings that the mechanism of phosphate onto inorganic wastes is mostly linked with the presence of the oxides of $\mathrm{Ca}, \mathrm{Al}$ and $\mathrm{Fe}$ which can effectively bind with phosphate in aqueous solution.

\subsubsection{Phosphate adsorbed on concrete sludge waste (CSW-P) as potential P-fertilizer}

Crop production is estimated to enhance of around $1.8 \%$ until the year 2050 what, inevitably, will lead in high demand for P-based fertilisers [40]. It is well-known that the world reserves of phosphate are dwindling [45]; therefore, it is imperative to search for new alternative sources of $\mathrm{P}$ aiming agricultural purposes. Mostly of $\mathrm{P}$ comes from phosphate rocks, and more than $80 \%$ of available phosphate rock contains deficient levels of $\mathrm{P}$ [40]. Therefore, land disposal may be a good option for the final destination of several solid residues, including alkaline CSWs. Although concrete wastes are considered dangerous residues, there are many similar residues disposed of in the soil for agricultural purposes [46]. 

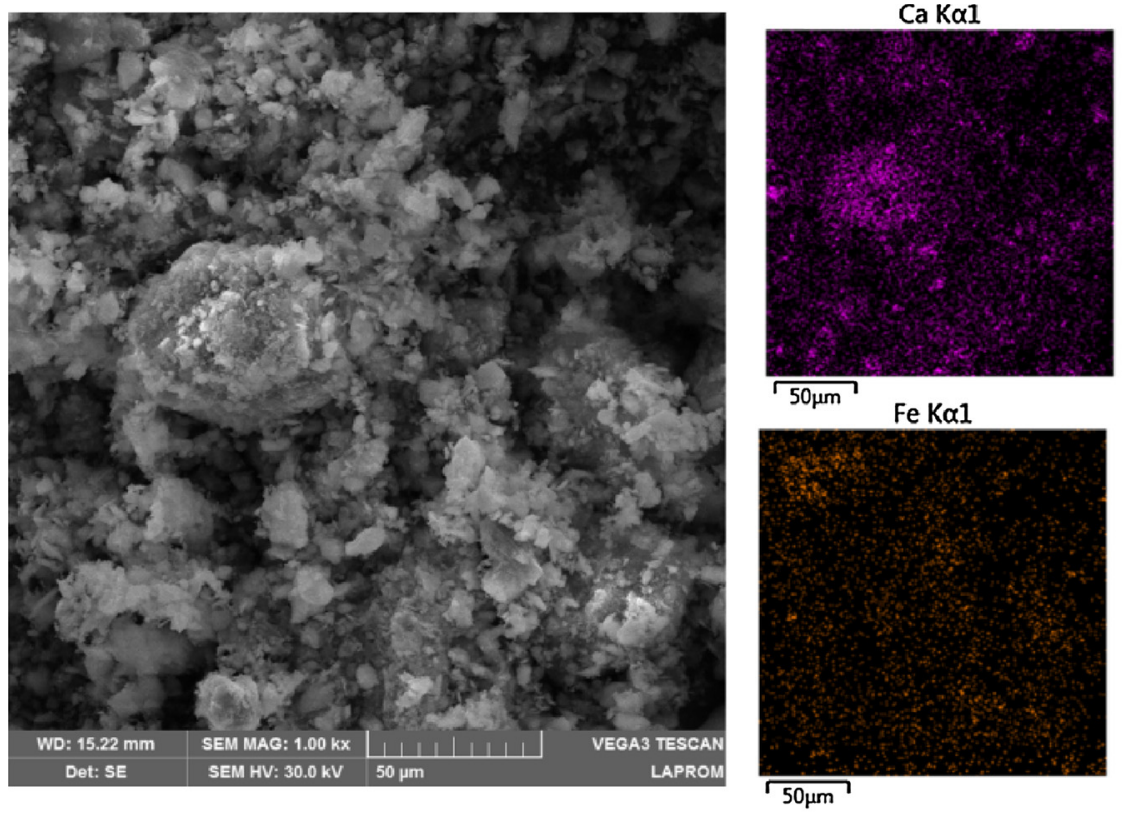
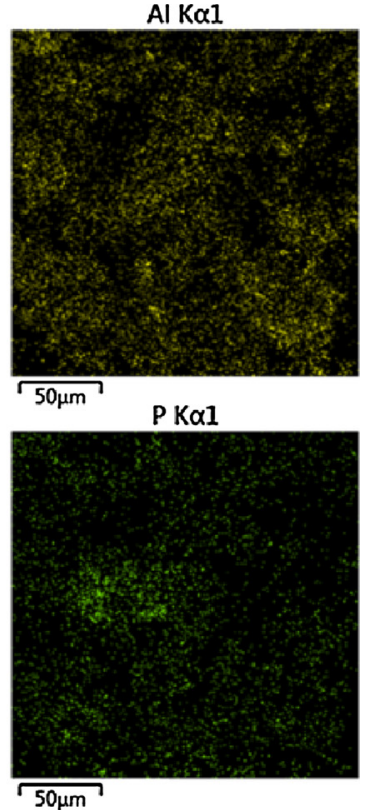

Fig. 10. SEM and EDS mapping of the main elements found in CSW-T loaded P.

Almeida et al. [46] evaluated the application of alkaline pulp industry waste as an alternative to correct the acidity of soils and concluded that it is a waste that can safely be used to improve the soil quality.

Another residue that has been used as a soil conditioner is steel slag $[47,48]$, this waste has a similar composition to CSW and yet so has proven to be a new soil conditioner $[47,48]$.

One of the main restrictions for the use of slags in the soil for crop production is the presence of heavy metals in its composition. However, compared to CSW, slags show to contain higher heavy metal contents, which is a useful data to be taken into consideration when CSW it is considered to be applied in the soil as fertiliser.

To the best of our knowledge, no work has been published dealing with CSW soil application. CSW-P application might favour the $\mathrm{pH}$ enhance and the availability of nutrients such as compounds of $\mathrm{Ca}, \mathrm{Mg}$, $\mathrm{Si}$ and adsorbed phosphate in the soil, resulting in an increase in the absorption of these elements by the plant, favouring the growth and yield of the crops $[47,48]$.

The application of CSW-P can happen something similar to what happens when slags are applied in the soil; it can neutralise part of the soil acidity, which occurs because these materials have neutralising base such $\mathrm{Ca}(\mathrm{OH})$ that reacts in water and releases hydroxyl groups (OH-).

Therefore, CSW adsorbed phosphate (CSW-P) contains some nutrients for the plants and does not contain too many heavy metals in it; it can be considered as a sustainable alternative CSW adsorbent to reclaim phosphate to develop new sustainable and eco-friendly strategies for better agricultural practices.

\section{Conclusion}

Cementitious wastes come as promising materials for the designing of inexpensive phosphate adsorbents because they contain many oxides and alkali calcium compounds that are effective in phosphate capture and recovery. The SEM images indicated slight differences between adsorbent microstructures. XRD results indicated that CSW-T presented different microstructures when compared with CSW, which reflected in their adsorption properties.

In the adsorption process, adsorbents dosage was found to have the most positive influence on the $\mathrm{P}$ removal. The influence of initial $\mathrm{pH}$ of the solution indicated that the maximum removal of $\mathrm{P}$ was obtained at $\mathrm{pH}$ 9.4. The adsorption capacity of phosphate increased with the increasing of temperature. These factors favoured the $\mathrm{Ca}^{+}$release into the solution and favouring the precipitation of calcium phosphate. CSW-T showed better adsorption properties compared to CSW. The kinetic data fitted well with Avrami's model suggesting that the phosphate removal on both adsorbents, CSW and CSW-T, have different adsorption mechanisms, which might be associated with the chemical adsorption as well with the formation of precipitates with phosphate.

The maximum adsorption capacities of phosphate P onto CSW and CSW-T were 24.04 and $57.64 \mathrm{mg} \mathrm{g}^{-1}$, respectively, at $22^{\circ} \mathrm{C}$, according to Liu isotherm highlighting heterogeneity in the adsorption of phosphate onto both adsorbents. The mechanism of the phosphate adsorption onto CSW indicated that the process was mainly controlled by chemical bonding or chemisorption. The adsorption capacity of phosphate for both CSW and CSW-T are higher than many adsorbents reported in the literature.

The inert part of construction and demolition wastes can be used as an effective and low-cost phosphorus-recovery adsorbent. Also, even thermally treated sample CSW-T having better efficiency in P removal, CSW is still the most cost-effective adsorbent because the heating process is expensive by demanding a high demand for energy.

This study also brought in light the alternative way of using CSW could be an advantage for real broad application for the agricultural field. Further studies on desorption and plant absorption are interesting to apply as phosphate loaded adsorbent fertiliser. However, aspects related to monitoring the presence of heavy metals must be better addressed and monitored as well as the $\mathrm{pH}$ change of the soils.

\section{Authors contribution}

Glaydson S. dos Reis - Designed and performed all experiments, analyzed data and co-wrote the paper.

Bogdan G. Cazacliu - helped to designed carbonation experiments, analyzed data and co-wrote the paper: Supervised the research.

Catalina Rodriguez - helped to perform adsorption experiments and co-wrote the paper.

Ekaterina Ovsyannikova - helped to perform adsorption experiments and co-wrote the paper.

Andrea Kruse - helped to perform adsorption experiments and co- 
wrote the paper: Supervised the research.

Eder Claudio Lima - helped to designed carbonation experiments, analyzed data and co-wrote the paper

Carlos Hoffmann Sampaio - aided in interpreting the results and worked on the manuscript; Supervised the research.

Guillherme Luiz Dotto - aided in interpreting the results and worked on the manuscript.

All authors discussed the results and commented on the manuscript.

\section{Declaration of Competing Interest}

None.

\section{Acknowledgement}

The authors thank the Foundation for Research Support of the State of Rio Grande do Sul (FAPERGS), National Council for Scientific and Technological Development (CNPq, Brazil) and Coordination of Improvement of Higher Education Personnel (CAPES, Brazil) for financial support and sponsorship. The authors also thank Mr Ferro, president of Esterel Terassement for financial support and for providing the Concrete sludge samples. Dr Glaydson Simões dos Reis is grateful to the CAPES for the postdoctoral scholarship granted through the National Postdoctoral Program (PNPD). We are also grateful to Chemaxon for giving us an academic research license for the Marvin Sketch software, Version 19.20.0, (http://www.chemaxon.com), 2019 used for calculation of phosphate species distribution.

\section{Appendix A. Supplementary data}

Supplementary material related to this article can be found, in the online version, at doi:https://doi.org/10.1016/j.jece.2019.103605.

\section{References}

[1] V.W.Y. Tam, M. Soomro, A.C.J. Evangelista, A review of recycled aggregate in concrete applications (2000-2017), Const. Build. Mat. 172 (2018) 272-292.

[2] T. Sasaki, Y. Sakai, T. Hongo, A. Iizuka, A. Yamasaki, Preparation of a solid adsorbent derived from concrete sludge and its boron removal performance, Ind. Eng. Chem. Res. 51 (2012) 5813-5817.

[3] H. Merrikhpour, M. Jalali, Waste calcite sludge as an adsorbent for the removal of cadmium, copper, lead, and zinc from aqueous solutions, Clean Technol. Environ. Policy 14 (2012) 845-855.

[4] J. Yoo, H. Shin, S. Ji, Evaluation of the applicability of concrete sludge for the removal of $\mathrm{Cu}, \mathrm{Pb}$, and $\mathrm{Zn}$ from contaminated aqueous solutions, Metals 8 (2018) 666, https://doi.org/10.3390/met8090666.

[5] M. Jelić, S. Šljivić-Ivanović, D. Dimović, M. Antonijević, M. Jović, I. Mirković, I. Smičiklas, The applicability of construction and demolition waste components for radionuclide sorption, J. Clean. Prod. 171 (2018) 322-332.

[6] N.J. Coleman, W.E. Lee, I.J. Slipper, Interactions of aqueous $\mathrm{Cu}^{2+}, \mathrm{Zn}^{2+}$ and $\mathrm{Pb}^{2+}$ ions with crushed concrete fines, J. Hazard. Mater. 121 (2005) 203-213.

[7] S. Egemose, M.J. Sønderup, M.V. Beinthin, K. Reitzel, C.C. Hoffmann, M.R. Flindt, Crushed concrete as a phosphate binding material: a potential new management tool, J. Environ. Qual. 41 (2012) 647-653.

[8] G.S. dos Reis, C.H. Sampaio, E.C. Lima, M. Wilhelm, Preparation of novel adsorbents based on combinations of polysiloxanes and sewage sludge to remove pharmaceuticals from aqueous solutions, Colloids Surf. A Physicochem. Eng. Asp. 497 (2016) 304-315.

[9] M.J. Puchana-Rosero, M.A. Adebayo, E.C. Lima, F.M. Machado, P.S. Thue, J.C.P. Vaghetti, C.S. Umpierres, M. Gutterres, Microwave-assisted activated carbon obtained from the sludge of tannery-treatment effluent plant for removal of leather dyes, Colloids Surf. A Physicochem. Eng. Asp. 504 (2016) 105-115.

[10] A.J.B. Leite, E.C. Lima, G.S. dos Reis, P.S. Thue, C. Saucier, F.S. Rodembusch, S.L.P. Dias, C.S. Umpierres, G.L. Dotto, Hybrid adsorbents of tannin and APTES (3aminopropyl-triethoxy-silane) and their application for the highly efficient removal of acid red 1 dye from aqueous solutions, J. Environ. Chem. Eng. 5 (2017) 4307-4318.

[11] G.S. dos Reis, M. Wilhelm, T.C.A. Silva, K. Rezwan, C.H. Sampaio, E.C. Lima, S.M.A.G.U. Souza, The use of the design of experiments for the evaluation of the production of surface-rich activated carbon from sewage sludge via microwave and conventional pyrolysis, Appl. Therm. Eng. 93 (2016) 590-597.

[12] P.S. Thue, M.A. Adebayo, E.C. Lima, J.M. Sieliechi, F.M. Machado, G.L. Dotto, J.C.P. Vaghetti, S.L.P. Dias, Preparation, characterization, and application of microwave-assisted activated carbons from wood chips for removal of phenol from aqueous solution, J. Mol. Liq. 223 (2016) 1067-1080.
[13] F.M. Kasperiski, E.C. Lima, C.S. Umpierres, G.S. dos Reis, P.S. Thue, D.R. Lima, S.L.P. Dias, C. Saucier, J.B. da Costa, Production of porous activated carbons from Caesalpinia ferrea seed pod wastes: highly efficient removal of captopril from aqueous solutions, J. Cleaner Prod. 197 (2018) 919-929.

[14] C.S. Umpierres, P.S. Thue, G.S. dos Reis, I.A.S. de Brum, E.C. Lima, W.A. de Alencar, S.L.P. Dias, G.L. Dotto, Microwave activated carbons from Tucumã (Astrocaryum aculeatum) waste for efficient removal of 2- nitrophenol from aqueous solutions, Environ. Technol. 39 (2018) 1173-1187.

[15] D. Sun, L. Hale, G. Kar, R. Soolanayakanahally, S. Adl, Phosphorus recovery and reuse by pyrolysis: applications for agriculture and environment, Chemosphere 194 (2018) 682-691.

[16] H. Ma, Y. Guo, Y. Qin, Y.-Y. Li, Nutrient recovery technologies integrated with energy recovery by waste biomass anaerobic digestion, Bioresour. Technol. Rep. 269 (2018) 520-531.

[17] E. Alavaisha, S. Manzoni, R. Lindborg, Different agricultural practices affect soil carbon, nitrogen and phosphorous in Kilombero -Tanzania, J. Environ. Manage. 234 (2019) 159-166.

[18] E.C. Lima, F. Barbosa-Jr, F.J. Krug, U. Guaita, Tungsten-rhodium permanent chemical modifier for lead determination in digests of biological materials and sediments by electrothermal atomic absorption spectrometry, J. Anal. At. Spectrom. 14 (1999) 1601-1605.

[19] E.C. Lima, R.V. Barbosa, J.L. Brasil, A.H.D.P. Santos, Evaluation of different permanent modifiers for the determination of arsenic, cadmium and lead in environmental samples by electrothermal atomic absorption spectrometry, J. Anal. At. Spectrom. 17 (2002) 1523-1529.

[20] E.C. Lima, J.L. Brasil, A.H.D.P. Santos, Evaluation of Rh, Ir, Ru, W-Rh, W-Ir, and W$\mathrm{Ru}$ as permanent modifiers for the determination of lead in ashes, coals, sediments, sludges, soils, and freshwaters by electrothermal atomic absorption spectrometry, Anal. Chim. Acta 484 (2003) 233-242.

[21] F. Barbosa-Jr, E.C. Lima, F.J. Krug, Determination of arsenic in sediment and soil slurries by electrothermal atomic absorption spectrometry using W-Rh permanent modifier, Analyst 125 (2000) 2079-2083.

[22] E.C. Lima, M.A. Adebayo, F.M. Machado, C.P. Bergmann, F.M. Machado (Eds.), Chapter 3: Kinetic and Equilibrium Models of Adsorption, in Carbon Nanomaterials as Adsorbents for Environmental and Biological Applications, Springer International Publishing, 2015, pp. 33-69.

[23] M. Thommes, K. Kaneko, A.V. Neimark, J.P. Olivier, F. Rodriguez-Reinoso, J. Rouquerol, Kenneth S.W. Sing, Physisorption of gases, with special reference to the evaluation of surface area and pore size distribution (IUPAC Technical Report), Pure Appl. Chem. 87 (2015) 1051-1069.

[24] M. River, C.J. Richardson, Particle size distribution predicts particulate phosphorus removal, Ambio 47 (Suppl. 1) (2018) S124-S133.

[25] S. Zhang, M. Zeng, J. Li, J. Li, J. Xu, X. Wang, Porous magnetic carbon sheets from biomass as an adsorbent for the fast removal of organic pollutants from aqueous solution, J. Mater. Chem. A Mater. Energy Sustain. 2 (2014) 4391-4397.

[26] M. Lee, I.S. Paik, I. Kim, H. Kang, S. Lee, Remediation of heavy metal contaminated groundwater originated from the abandoned mine using lime and calcium carbonate, J. Hazard. Mater. 144 (2007) 208-214.

[27] M. Komárek, A. Vanek, V. Ettler, Chemical stabilization of metals and arsenic in contaminated soils using oxides-a review, Environ. Pollut. 172 (2013) 9-22.

[28] J. Choi, J. Chung, W. Lee, J.-O. Kim, Phosphorous adsorption on synthesized magnetite in wastewater, J. Ind.Eng. Chem. 34 (2016) 198-203.

[29] J. Xie, Z. Wang, S. Lu, D. Wu, Z. Zhang, H. Kong, Removal and recovery of phosphate from water by lanthanum hydroxide materials, Chem. Eng. J. 254 (2014) 163-170.

[30] X. Yuan, W. Xia, J. An, J. Yin, X. Zhou, W. Yang, Kinetic and thermodynamic studies on the phosphate adsorption removal by dolomite mineral, J. Chem. 853105 (2015) 8, https://doi.org/10.1155/2015/853105.

[31] J. Yan, D.W. Kirk, C.Q. Jia, X. Liu, Sorption of aqueous phosphorus onto bituminous and lignite coal ashes, J. Hazard. Mat. 148 (2007) 395-401.

[32] M. Oliveira, A. Araújo, G. Azevedo, M.F.R. Pereira, I.C. Neves, A.V. Machado, Kinetic and equilibrium studies of phosphorous adsorption: effect of physical and chemical properties of adsorption agent, Ecol. Eng. 82 (2015) 527-530.

[33] Y. Deng, A. Wheatley, Mechanisms of phosphorus removal by recycled crushed concrete, Int. J. Environ. Res. Public Health 15 (2018) 357, https://doi.org/10. 3390/ijerph15020357.

[34] J.R. Fink, A.V. Inda, T. Tiecher, V. Barrón, Iron oxides and organic matter on soil phosphorus availability, Cienc. Agrotec. 40 (2016) 369-379.

[35] Q. Hou, P. Meng, H. Pei, W. Hu, Y. Chen, Phosphorus adsorption characteristics of alum sludge: adsorption capacity and the forms of phosphorus retained in alum sludge, Mater. Lett. 229 (2018) 31-35.

[36] K. Kang, C.-G. Lee, J.-W. Choi, S.-G. Hong, S.-J. Park, Application of thermally treated crushed concrete granules for the removal of phosphate: a cheap adsorbent with high adsorption capacity, Water Air Soil Pollut. 228 (2017) 8, https://doi.org/ 10.1007/s11270-016-3196-1.

[37] F. Li, W. Wu, R. Li, X. Fu, Adsorption of phosphate by acid-modified fly ash and palygorskite in aqueous solution: experimental and modelling, Appl. Clay Sci. 132-133 (2016) 343-352.

[38] Z.L. Shi, Fu-M. Liu, S.-h. Yao, Adsorptive removal of phosphate from aqueous solutions using activated carbon loaded with Fe(III) oxide, New Carbon Mater. 26 (2011) 299-306.

[39] L. Yuan, Z. Qiu, L. Yuan, M. Tariq, Y. Lu, J. Yang, Z. Li, S. Lyu, Adsorption and mechanistic study for phosphate removal by magnetic Fe3O4-doped spent FCC catalysts adsorbent, Chemosphere 219 (2019) 183-190.

[40] T. Falayi, Alkaline recovery of phosphorus from sewage sludge and stabilisation of sewage sludge residue, Waste Manage. 84 (2019) 166-172. 
[41] E.C. Lima, A.R. Cestari, M.A. Adebayo, Comments on the paper: a critical review of the applicability of Avrami fractional kinetic equation in adsorption-based water treatment studies, Desalin. Water Treat. 57 (2016) 19566-19571.

[42] X.D. Cao, W. Harris, Carbonate and magnesium interactive effect on calcium phosphate precipitation, Environ. Sci. Technol. 42 (2008) 436-442.

[43] Z. Zhang, X. Wang, J. Zhao, Phosphate recovery from wastewater using calcium silicate hydrate (C-S-H): sonochemical synthesis and properties, Environ. Sci. Water Res. Technol. 5 (2019) 131-139.

[44] J. Zhang, C. Shi, Y. Li, X. Pan, C.-H. Poon, Z. Xie, Performance enhancement of recycled concrete aggregates through carbonation, J. Mater. Civ. Eng. 27 (2015) 04015029.
[45] D.A. Vaccari, N. Strigul, Extrapolating phosphorus production to estimate resource reserves, Chemosphere 84 (2011) 792-797.

[46] H.C. Almeida, C.B. da Silveira, P.R. Ernani, M.L. Campos, D. Almeida, Composição química de um resíduo alcalino da indústria de papel e celulose (dregs), Quim. Nova 30 (2007) 1669-1672.

[47] D. Ning, A. Song, F. Fan, Z. Li, Y. Liang, Effects of slag-based silicon fertiliser on rice growth and brown-spot resistance, PLoS One 9 (2014) e102681, , https://doi.org/ 10.1371/journal.pone.0102681.

[48] M.P.B. Filho, F.J.P. Zimmermann, O.F. Silva, Influence of calcium silicate slag on soil acidity and upland rice grain yield, Cienc. Agrotec. 28 (2004) 323-331. 